\title{
Nutritional Requirements for Maternal and Newborn Health
}

\author{
Maria-Raquel G. Silva ${ }^{\text {a,b,c, }}$ and Maria Luisa Bellotto ${ }^{\mathrm{d}}$
}

${ }^{a}$ Department of Nutrition, Faculty of Health Sciences, University Fernando Pessoa, Oporto, Portugal; ${ }^{b}$ Research Centre for Anthropology and Health, University of Coimbra, Coimbra, Portugal; ${ }^{c}$ Scientific Commission of the National School of Gymnastics, Gymnastics Federation of Portugal, Lisbon, Portugal; ${ }^{d}$ Department of Exercise Physiology, Faculty of Physical Education, University of Campinas, Campinas, Brazil

\begin{abstract}
During pregnancy, dietary energy and nutrient requirements are increased to support metabolism changes of the mother, as blood volume and red cells expansion, and the delivery of energy and nutrients to the fetus. This review aims to: i) identify and discuss maternal physiological changes during pregnancy related to nutrition; ii) clarify about the most recently

M.R.G. Silva nutritional recommendations for pregnant women, including special groups of pregnant women, who do not usually practice a healthy diet, those who are in high-risk categories and pregnant athletes; iii) and clarify the importance of breastfeeding, specifically for the newborn, and infant formulae, as an alternative feeding. A literature review was undertaken by electronic databases PubMed, b-on, Scielo, Medline, Web of Science and Science Direct. The most recent original articles, systematic reviews and meta-analyses were used to search information from pregnancy, newborn baby, postpartum and nutritional status. The intake of whole grains, fruit, vegetables, low-fat dairy and lean meats can be preventive for an appropriate maternal weight and infant weight. Supplements should only be used when there is a deficiency. Special groups of pregnant women who do not usually practice a healthy diet, those who are in high-risk categories and pregnant athletes should daily take a multivitamin andmineral preparation containing a variety of nutrients beginning in the second trimester. A healthy diet and an appropriate body weight are mandatory for maternal health and fetal outcomes. Breast milk is a unique source of energy and nutrients for the infant.
\end{abstract}

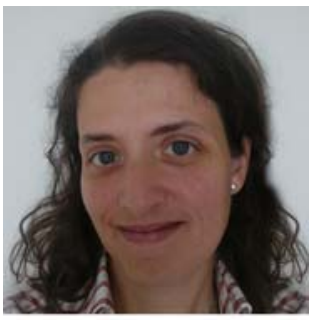

Keywords: Energy, fetus health, infant health, maternal health, nutrients, special groups.

\section{INTRODUCTION}

A healthy nutritional status is an undoubtable prerequisite for a normal pregnancy, a healthy newborn and a successful postpartum. However, time has showed an evolutionary perspective when considering the potential effect of inadequate energy availability to the fetus development [1]. Several studies from the $50 \mathrm{~s}$ and $60 \mathrm{~s}[2,3]$ showed that pregnant women with not enough weight gain presented higher risk of premature birth than those with adequate weight gain. Therefore, in that time, undernutrition was seen as a negative influence factor for the pregnancy outcome. Nowadays, the opposite significant complication of pregnancy, which is maternal overweight and obesity worldwide $[4,5]$, is preoccupying medical and scientific communities, since the fetus may be exposed to an excessive energy availability. During pregnancy, total energy and nutrient requirements are increased in order to support the mother's metabolism changes, asblood volume and red cells expansion, and the delivery of energy and nutrients to the fetus $[1,6]$.

Unfortunately, as seen in a recent systematic review and meta-analysis of 90 studies about nutritional intake among pregnant women in developed countries $(\mathrm{n}=126.242)$,

*Address correspondence to this author at the Department of Nutrition, Faculty of Health Sciences, University Fernando Pessoa, Oporto, Portugal; Tel: +351 22 5074630; Fax: +351 22 5074637; E-mail: raquel@ufp.edu.pt energy and fiber intakes were generally lower, carbohydrate intake was borderline or lower and total fat and saturated fat intakes were higher than nutritional recommendations of each specific country [7]. Moreover, it was recently indicated that micronutrient intake during pregnancy is less than needed [7], which is of great preocupation since the current consensus lies on the impact of maternal nutrition in both short and long-term health of the child [1].

In addition, although there are various factors that can negatively affect the maternal nutritional status, such as inadequate energy availability [1], physical inactivity, overweight or obesity [4] and other complications (multiple pregnancies, being an adolescent, alcohol and tobacco consumption and drugs [8], maternal physiological changes influence nutritional status by increasing energy and nutritional needs [9-12]. Those changes can influence not only the mother's health, but also fetus growth and development [9]. Although the evaluation of the maternal nutritional status before conception is important to identify and to correct eventual disorders or energy imbalances and other behaviors and to prevent future complications during pregnancy and in postpartum [4, 10], attempting to study inferences of maternal nutrition status in the fetal growth is difficult [1].

Therefore, this review aims to: i) identify and discuss maternal physiological changes during pregnancy related to nutrition; ii) clarify about the most recently nutritional recommendations for pregnant women, including special 
groups of pregnant women, who do not usually practice a healthy diet, those who are in high-risk categories (pregnant women carrying more than one fetus, women who are high cigarette smokers, heavy alcohol consumers and drug abusers) and pregnant athletes; iii) and clarify the importance of breastfeeding, specifically for the newborn, and infant formulae, as an alternative feeding.

\section{METHODS}

A comprehensive literature review was undertaken by electronic databases as PubMed, b-on, Scielo, Medline, Web of Science and Science Direct. The most recent original articles, systematic reviews and meta-analyses were used to search information from pregnancy, newborn baby, postpartum and nutritional status. Reviews were searched for using the keywords "nutrition during pregnancy", "diet during pregnancy", "body composition during pregnancy", "breastfeeding AND mother", "breastfeeding AND newborn", "infant formulae AND nutrition". Articles were limited to studies published in English, Portuguese and Spanish.

\section{PHYSIOLOGICAL MODIFICATIONS NUTRITIONAL NEEDS DURING PREGNANCY}

AND

Various physiological modifications occur in the pregnant woman's body in order to support fetus growth and development, and to assure mother's health. Therefore, increases in plasma volume and extracellular fluids; changes in maternal tissues, including mammary glands, uterus, placenta and adipose stores and the production of amniotic liquid are observed [13]. Plasma volume expands nearly $50 \%$ and the increased production of erythrocytes promotes iron, folate and vitamin B-12 needs.

Hormonal changes prepare the pregnant woman for lactation and body composition is characterized by weight gain and a higher body fat and fat-free mass than in prepregnancy $[13,14]$.

Therefore, woman's body weight prior to conception seems to have a great impact on her health and on her child given the strong association between childhood obesity and other metabolic problems, such as diabetes, hypertension and cardiovascular diseases [1]. Moreover, as the mother's body weight in pre -pregnancy appears to be more important than the body weight gained during the pregnancy, it is crucial that women strive to approach a normal body weight before pregnancy.

On the other hand, another important physiological change during pregnancy is the slight increase in resting energy expenditure, mainly in the second and the third trimesters, so energy availability is mostly dependent on energy expenditure rate (i.e. physical activity) that varies widely [15].

In accordance with the Subcommittee on Nutritional Status and Weight Gain during Pregnancy of the Institute of Medicine (IM), the adequate gestational weight gain for normal weight women varies from 11 to $16 \mathrm{~kg}$ [16]. Recently, in 2014, the German National Consensus Recommendations on Nutrition and Lifestyle in Pregnancy by the 'Healthy Start - Young Family Network' considered the appropriate gestational weight gain for normal weight women from 10 to $16 \mathrm{~kg}$ [17].

\section{Overweight and Obesity During Pregnancy}

It has been observed a preoccupying increase of overweight and obesity in pregnant women worldwide [18]. Although maternal obesity and non-expected perinatal outcomes have been reported, it has not been yet established a biologic pathway [1].

Epidemiological studies have demonstrated that maternal overweight and obesity can bring several health complications for the pregnancy and the partum, and might compromise the fetus's health, as follows: high blood pressure, gestational diabetes [11], preeclampsia, prolonged labor, unplanned cesarean and difficulties in breastfeeding $[12,14]$.

As it is well known, placenta is responsible for the delivery of nutrients, oxygen and hormones to the fetus and, obviously, for fetus growth and development [19]. It has recently reported that maternal obesity is associated with placenta inefficiency, increased placental lesions [20], woman's undernutrition and neonatal consequences, including intrauterine growth restriction [21], and altered epigenetic programming [22].

Therefore, a healthy body weight in pre-pregnancy and during pregnancy is crucial for an adequate maternal body mass index and for the health outcome of offspring in adulthood. On the other hand, an excessive body mass index can negatively affect fetus, in the short and long term and, thus, it plays a determinant role in altered utero environment [1].

Several others consequences of maternal obesity affecting negatively maternal and fetus health have recently been reported. For example, chronic inflammation is common in obesity and in pregnancy [1], since it was demonstrated that pro-inflammatory cytokines are increased in obese pregnants [23] increasing risks of fetal infection and complications [24]. The elevated oxidative stress [25] as a result of maternal obesity may impair fetal metabolism during placentation and establishment of blood supply [26].

\section{Weight Gain During Pregnancy}

The increase of pre-pregnancy body mass index is associated with an increase of placental weight and size and also associated with adverse perinatal outcomes [19]. Prepregnancy weight-for-height and consecutives weight measurements are the only anthropometric measurements documented for assessing the gestational weight gain [16].

Body mass index (BMI) is defined as weight $(\mathrm{kg})$ $/$ height $^{2}\left(\mathrm{~m}^{2}\right)$ and it is a better indicator of nutritional status than weight itself. Therefore, the Subcommittee on Nutritional Status and Weight Gain During Pregnancy of the Committee on Nutritional Status During Pregnancy and Lactation, IM [16] agreed on the following BMI categories in attempting short and long-term health of the mother and the child, as follows: underweight: BMI $<19.8 \mathrm{~kg} / \mathrm{m}^{2}$; normal weight: $\mathrm{BMI} \geq 19.8$ to $26.0 \mathrm{~kg} / \mathrm{m}^{2}$; overweight: BMI $>26.0$ to $29.0 \mathrm{~kg} / \mathrm{m}^{2}$ and; obese: $\mathrm{BMI}>29.0 \mathrm{~kg} / \mathrm{m}^{2}$. 
Consequently, the recommended total weight gain ranges for pregnant women by pre-pregnancy BMI are as follows [16]: 12.5 to $18.0 \mathrm{~kg}$ for low BMI $\left(<19.8 \mathrm{~kg} / \mathrm{m}^{2}\right) ; 11.5$ to $16.0 \mathrm{~kg}$ for normal BMI ( $\geq 19.8$ to $\left.26.0 \mathrm{~kg} / \mathrm{m}^{2}\right) ; 7.0$ to $11.5 \mathrm{~kg}$ for high BMI (>26.0 to $\left.29.0 \mathrm{~kg} / \mathrm{m}^{2}\right)$ and; at least $6.8 \mathrm{~kg}$ as the target weight gain for extremely obese women $\left(\mathrm{BMI}>29.0 \mathrm{~kg} / \mathrm{m}^{2}\right)$. The Subcommittee also recommended that young adolescent and black women should gain weight at the upper end of the recommended range and short women (height $<157 \mathrm{~cm}$ ) should gain at the lower end of the target weight gain range for theirs weight for height. For women carrying twins, the recommended target total weight gain at term is 16.0 to $20.5 \mathrm{~kg}$. This subcommittee also highlights that women with a normal weight pre-pregnancy should gain rate of approximately $0.4 \mathrm{~kg}$ per week in the second and third trimesters of pregnancy, while underweight women should gain slightly higher, $0.5 \mathrm{~kg}$ per week and, overweight women should gain not more than $0.3 \mathrm{~kg}$ per week, and extremely obese should reach the target rate defined on an individual basis, according to an individual dietary assessment and nutritional counseling [16].

\section{Energy and Nutrients Requirements}

The practice of a healthy nutritional intake must be reached by an adequate energy availability, including key micronutrients, especially iron, folate, zinc, calcium, vitamin $\mathrm{D}$, and essential fatty acids in order to promote red blood cell production, bone development, enzyme activity and brain development [1].

For a reference 19-year old active woman, the estimated average energy requirements, such as $2740 \mathrm{kcal} /$ day and $2852 \mathrm{kcal} /$ day are recommended for the second and the third semesters of pregnancy, respectively (Table 1), in accordance with the Recommended Dietary Allowances (RDA) from the Food and Nutrition Board/Institute of Medicine (FNB/IM) [27]. An average energy increase of $14 \%$ to $18 \%$ (mean of $16 \%$ - Fig. 1) is estimated to be the recommended during pregnancy. However, the German National Consensus Recommendations on Nutrition and Lifestyle in Pregnancy by the 'Healthy Start - Young Family Network considers the increase of only $10 \%$ more energy intake by the end the pregnancy [17], relying on the slight increases in energy needs, as mentioned before.

Regarding micronutrients, energy needs increase much more than for macronutrients (Fig. 1). Even prior to conception, an increased average intake of folate, iodine and iron is recommended [17]. However, only in the beginning of the second trimester, a marked increase in vitamins and minerals is observed, as can be seen in Table $\mathbf{1}$ and in Fig. 1.

Although RDAs for vitamins $\mathrm{D}, \mathrm{E}$ and $\mathrm{K}$, biotin, sodium, potassium, chloride, calcium, phosphorus and fluoride are not increased during pregnancy, estimated energy (as mentioned before), protein, specific vitamins (vitamin A, thiamin, niacin, panthogenic acid, vitamin B-6, folate, vitamin B-12, vitamin C) and minerals (choline, magnesium, iron, zinc, selenium, iodine, copper, manganese, chromium and molybdenum) requirements are increased in the second and the third trimesters (Fig. 1). In relation to fiber intake, the FNB/IM recommends an average intake for total fiber of
Table 1. Estimated energy and nutrients requirements for a reference 19-year old active woman according to the Food and Nutrition Board, Institute of Medicine [2732].

\begin{tabular}{|c|c|c|}
\hline DRI's & Nonpregnant & Pregnant \\
\hline $\operatorname{EER(kcal/day)~}$ & 2400 & $2740-2852^{\mathrm{a}}$ \\
\hline Carbohydrate(g/day) & 130 & 175 \\
\hline Protein(g/day) & 46 & 71 \\
\hline Vitamin $\mathrm{A}(\mu \mathrm{g} /$ day $)$ & 700 & 770 \\
\hline Vitamin $\mathrm{D}(\mu \mathrm{g} /$ day $)$ & 5 & 5 \\
\hline Vitamin E(mg/day) & 15 & 15 \\
\hline Vitamin $\mathrm{K}(\mu \mathrm{g} /$ day $)$ & 90 & 90 \\
\hline Thiamin(mg/day) & 1.1 & 1.4 \\
\hline Riboflavin(mg/day) & 1.1 & 1.4 \\
\hline Niacin(mg/day) & 14 & 18 \\
\hline Panthogenic acid(mg/day) & 5 & 6 \\
\hline $\operatorname{Biotin}(\mu \mathrm{g} /$ day $)$ & 30 & 30 \\
\hline Vitamin B-6(mg/day) & 1.3 & 1.9 \\
\hline Folate( $\mu \mathrm{g} /$ day $)$ & 400 & 600 \\
\hline Vitamin B-12( $\mu \mathrm{g} /$ day $)$ & 2.4 & 2.6 \\
\hline Vitamin C(mg/day) & 75 & 85 \\
\hline Choline(mg/day) & 425 & 450 \\
\hline Sodium(g/day) & 1.5 & 1.5 \\
\hline Potassium(mg/day) & 4.7 & 4.7 \\
\hline Chloride(g/day) & 2.3 & 2.3 \\
\hline Calcium(mg/day) & 1000 & 1000 \\
\hline Phosphorus(mg/day) & 700 & 700 \\
\hline Magnesium(mg/day) & 310 & 350 \\
\hline $\operatorname{Iron}(\mathrm{mg} /$ day) & 18 & 27 \\
\hline Zinc(mg/day) & 8 & 11 \\
\hline $\operatorname{Selenium}(\mu \mathrm{g} /$ day $)$ & 55 & 60 \\
\hline Iodine( $\mu \mathrm{g} /$ day $)$ & 150 & 220 \\
\hline Copper( $\mu \mathrm{g} /$ day $)$ & 900 & 1000 \\
\hline Manganese(mg/day) & 1.8 & 2 \\
\hline Fluoride(mg/day) & 3 & 3 \\
\hline Chromium( $\mu \mathrm{g} /$ day $)$ & 25 & 30 \\
\hline Molybdenum( $\mu \mathrm{g} /$ day $)$ & 45 & 50 \\
\hline Water(L/day) & 2.7 & 3.0 \\
\hline
\end{tabular}

${ }^{\text {a }}$ The lower value indicates the second trimester and the highest value indicates the third trimester.

$28 \mathrm{~g} /$ day for a pregnant woman $(14 \mathrm{~g} / 1.000 \mathrm{kcal} \times 1.978$ $\mathrm{kcal} / 1.000 \mathrm{kcal} /$ day), slightly higher than the estimated for a 


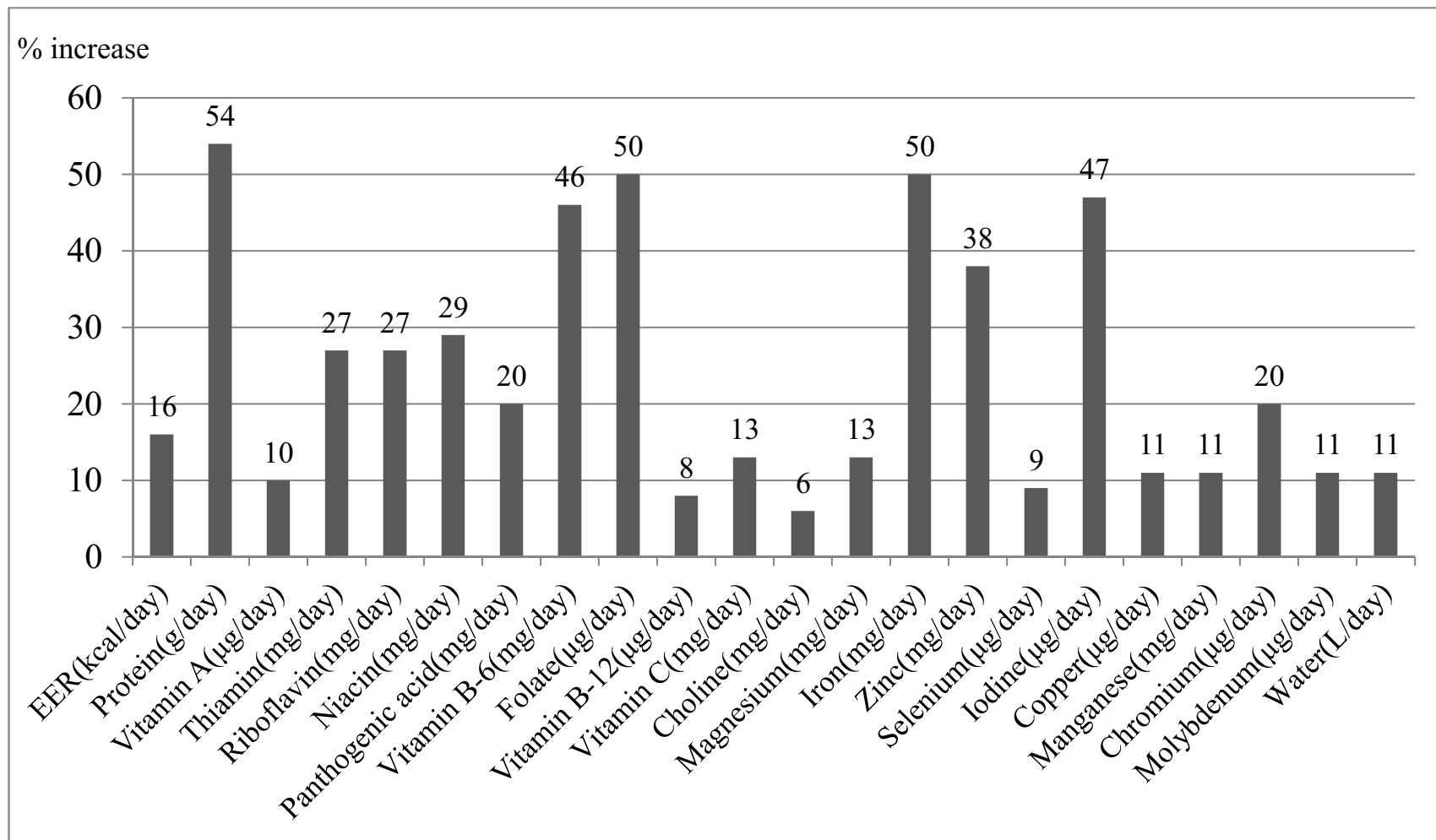

Fig. (1). Percentage of needs increase for energy and nutrients requirements in the second and the third trimesters of pregnancy according to the Food and Nutrition Board, Institute of Medicine [27-32].

non-pregnant woman ( $25 \mathrm{~g} /$ day) [27]. For water intake (from beverages, foods and drinking water), the FNB/IM recommends an increase from $2.7 \mathrm{~L}$ for a non-pregnant women to $3.0 \mathrm{~L}$ for a pregnant women in order to meet hydration needs [32].

\section{Macronutrients}

For a reference 19-year old active woman, the RDA from the FNB/IM estimates that the average energy requirements for protein in a pregnant woman are 54\% elevated $(71 \mathrm{~g} /$ day - Table 1) than in a non-pregnant woman (46 g/day) [27, 33]. These higher levels of protein during pregnancy are recommended for the synthesis of new maternal, fetal and placental tissues, which can be obtained by a normal and healthy diet with low-fat milk and milk products, eggs, lowfat meats and meat products, legumes and grain products [1].

Although carbohydrate is the main source of energy, its daily amount intake should be slightly increased from 130 $\mathrm{g} /$ day in pre-pregnancy to $175 \mathrm{~g} /$ day during pregnancy [27]. Complex carbohydrates intake should be especially emphasized, such as rice, pasta, whole-grain breads and fortified cereals.

Fat is important to supply minimal amounts of essential fatty acids, fat-soluble vitamins and to support breastfeeding. Recent evidence suggests that high fat consumption during pregnancy regulate the appetite system of babies towards orexigenic pathways, leptin resistance, and adiposity [34]. Therefore, the IM recommends mainly polyunsaturated fatty acids [27].

\section{Micronutrients}

\section{$\underline{\text { Iron }}$}

Iron is the only known nutrient for which requirements cannot be met reasonably by diet alone. This mineral is crucial for the hemoglobin production in order to expand the red cell mass for fetal accommodation, placental growth and development, and also permits blood loss that may occurs at delivery $[1,16]$. Maternal iron deficiency can lead to negative consequences in birth outcomes, i.e. fetal growth restriction and preterm birth, which are associated with infant and child mortality [35]. For example, isolated hypothyroxinemia during early pregnancy may irreversibly damage offspring's neurodevelopment [36]. Although its causes are not well studied, it was demonstrated an association between iron deficiency and isolated hypothyroxinemia in both pregnant and childbearing-aged women, independently of the effects of iodine and thyroid autoimmunity.

The iron deficiency in women with or without anemia seems to increase as pregnancy advances [37]. Therefore, an increase of $50 \%$ as demonstrated in Fig. 1 can be justified by the fact that a woman daily needs to absorb approximately 3 $\mathrm{mg}$ of iron in addition to the amount of iron normally absorbed from daily food [16]. In fact, a low-dose supplement of iron (e.g., $30 \mathrm{mg}$ of ferrous iron daily) is indicated as providing that amount of extra iron [16]. However, in a study conducted in 1196 non-anaemic pregnant women, iron supplementation with a prescribed 
dose of $45 \mathrm{mg} /$ day was not beneficial, as adverse effects were observed [38]. These authors concluded that an individualized approach for antenatal iron supplementation should be warranted, mainly in non-anaemic women. In regarding to those who normally present iron deficiency, the Subcommittee considers that low-doses iron are more advantageous over higher-dose, because low-doses iron supplements are less potential for undesirable nutrientnutrient interactions, have a more efficient absorption, and have a less risk of causing gastrointestinal distress [16, 28].

\section{Folate}

This mineral should be increased from $400 \mu \mathrm{g} /$ day in prepregnancy to $600 \mu \mathrm{g} /$ day during gestation [29], i.e. an increase of $50 \%$ is necessary due to the demand of fetal growth and to mostly prevent fetus neural tube defects [1, 16]. Women who demonstrate a poor diet in whole-grain or fortified cereals, fruit and green vegetables may be at risk for a low folate intake [16]. Ideally, that folic supplement should be taken three months earlier to the conception or in the beginning of pregnancy $[16,39]$, if there are doubts about that normal intake of folate.

\section{Iodine}

An increase of $47 \%$ in iodine intake is recommended from pre-pregnancy $(150 \mu \mathrm{g} /$ day $)$ to pregnancy $(220 \mu \mathrm{g} /$ day $)$ [28]; additional 50 to $70 \mu \mathrm{g} /$ day is sufficient to avoid iodine deficiency and consequently the risk of hypothyroidism in adult women [16]. Iodine is a basic component of thyroid hormones thyroxine and triiodothyronine and, in cases of its deficiency, it should be taken prior to conception, since during pregnancy it promotes a wide spectrum of disorders in the fetus and in the offspring, such as stillbirth, absorptions, and congenital anomalies; endemic cretinism; spastic dysplegia; or the myxedematous type of cretinism $[16,28]$.

\section{$\underline{\text { Zinc }}$}

Dietary zinc intake should increase from $8 \mathrm{mg} /$ day in non-pregnant women to $11 \mathrm{mg}$ /day in pregnant women [28]. Zinc is determinant for the fetus development and for maternal uterine muscle development. Evidence has demonstrated that zinc absorption is similar in non-pregnant women and in pregnant women; however, it was demonstrated to be increased in lactation [40].

\section{Calcium}

In accordance with the RDA for calcium, a pregnant woman does not need additional calcium [31], since its transport is made across the placenta through an active and important process for skeletal development and other metabolic functions; it occurs against a concentration gradient, involving placental calcium-binding protein [16]. Calcium is deposited in the fetus mostly in the last trimester, which is cleared by the increased efficiency of maternal intestinal absorption at least the second trimester [17]. This increased efficiency of maternal intestinal absorption may be due to the rise on calcitonin that might protect maternal skeletal against reabsorption [41]. In cases of younger women (under age of 25 years old) with low calcium intake $(<600 \mathrm{mg} /$ day $)$, it is recommended to preferably increase the consumption of calcium by food sources like milk or cheese, and the last option should be a supplement of calcium of 600 $\mathrm{mg} /$ day [16].

\section{$\underline{\text { Vitamin D }}$}

According to the IM, the estimated average requirement for vitamin $\mathrm{D}$ is similar in non-pregnant women and during gestation (5 $\mu \mathrm{g}$ /day) [31].

Maternal vitamin D deficiency is common during pregnancy and it has been suggested that maternal vitamin $\mathrm{D}$ status in pregnancy is determinant for bone-mineral content in babies. A longitudinal study conducted in 198 children born demonstrated an association between maternal vitamin $\mathrm{D}$ insufficiencies with reduced bone-mineral accrual in the baby during childhood mediated in parts through the concentration of calcium in the umbilical venous [42]. However, in a recent and large prospective study (3960 mother-and-offspring pairs) there was no relevant association between vitamin $\mathrm{D}$ status in pregnancy and offspring bone-mineral content in late childhood [43].

In accordance with a recent comprehensive review of the literature, vitamin D supplementation is not required for pregnant women who are regularly exposed to sunlight [1]. On the other hand, according to the National Health and Medical Research Council pregnant women who have little access to sunlight, especially during winter months, a vitamin D supplement of $10 \mu \mathrm{g} /$ day [44] is not excessive and it could lead to long lasting reductions in the risk of osteoporotic fracture in their offspring [42].

\section{Vitamin B-6}

The average estimated requirement of vitamin B-6 by the $\mathrm{FNB} / \mathrm{IM}$ for a non-pregnant woman is $1.3 \mathrm{mg} /$ day and for a pregnant woman is $1.9 \mathrm{mg} /$ day [29]; thus an increase of $46 \%$ is expected, because of its important role in protein, carbohydrate, and lipid metabolism, and in immune and hormonal systems [16], but evidence is inclusive. Although evidence have demonstrated that vitamins B-6 and B-12 are related to prevent neural tube defects in folatefortified populations, a recent study demonstrated that supplementation during pregnancy is not appropriate in a cohort of women considered to be healthy and a low risk for nutritional deficiencies [45]. Already in 2015, the B-vitamin status and birth outcomes were studied in 999 Asian pregnant women of 26 to 28 weeks of gestation. Although authors observed higher folate concentrations in late pregnancy associated with longer gestational age and probably were in the other hand associated with a lower risk of preterm birth, they also found almost no benefit of higher folate concentrations and the reduced risk of being small for gestational age or of higher vitamin B-6 and vitamin B-12 concentrations the reduced risk of preterm birth or being small for gestational age [46].

\section{$\underline{\text { Niacin }}$}

Niacin is needed during pregnancy in amounts approximately proportional to the increased energy requirements, i.e. the estimated energy requirements for niacin are $29 \%$ higher in a pregnant woman $(18 \mathrm{mg} /$ day) than in a non-pregnant woman (14 $\mathrm{mg} /$ day) [29]. The reason 
for this is that niacin takes part in all cells structures and participates in various metabolic processes, such as glycolysis, fatty acid metabolism, and tissue respiration [16].

\section{General Dietary Recommendations During Pregnancy}

Nutritional education and counselling strategies should consider the multiple real-world dimensions of decisionmaking around food and supplements [47].

Every pregnant woman should read food labelling to make healthy dietary choices [48], including sodium content. As in pre-pregnancy, pregnant women should eat regularly in order to avoid excessive hunger.

The breakfast, the first meal of a day should be complete, varied and balanced; it should include fruit, wholegrains and low-fat milk or milk products. Skipping meals increases the risk of being overweight and obese [49, 50], increases BMI [51] and the consumption of energy-dense foods [52].

Soup is an intelligent resource to eat vegetables [16] twice a day, at the beginning of two important meals (lunch and dinner), and it also helps in regulating the appetite for the rest of the meal. However, vegetables and fruit should be eaten in-between-meal snacks to improve adequate fiber intake and mostly to avoid energy-dense foods rich in sugar and fat [48].

A pregnant woman's favorite drink should be plain water; it has predicted a lower energy density of the foods consumed. Instead, high consumption of sweetened beverages can contribute to increase energy intake and consequently body weight gain [53] and has predicted higher energy density of foods consumed [54]. Fish is preferable than meat, since it can be richer in long chain omega-3 polyunsaturated fatty acids [55], which are important for intrauterine growth. Lean meat contributes to prevent some micronutrients deficiencies (e.g. iron, vitamin B-12, pantothenic acid) [16].

In summary, foods such as lean meat, vegetables, fruit, whole grains, and low-fat dairy are all healthy food choices, because of the beneficial nutrients such as protein, fiber, iron, zinc, calcium, and folate, which are crucial for the maternal health and the fetus health.

All these recommendations would not be completed if an important vector of the concept of a healthy lifestyle during pregnancy was not mentioned, that is regular, daily exercise (exercise of moderate intensity); it is much desirable.

Alcohol and tobacco consumption and illicit drugs use prior to pregnancy should be avoided, because they increase the risk to enter pregnancy with a low BMI and nutritional deficiencies and can harm the unborn child [17]. Alcohol and tobacco during pregnancy increase the risk of miscarrying, delivering a stillborn baby, giving birth prematurely and delivering a low-birth-weight infant [17] that may present various impairments both physical and neuropsychological, including certain fetus's syndromes (e.g. fetal alcohol syndrome) [56]. The consumption of caffeinated beverages should be in moderate amounts; not more than 3 cups of coffee per day [57].

\section{Special Nutritional Supervision for Special Groups of Pregnant Women}

There are some groups of pregnant women who are more sensitive for the development of an insufficient or an excessive body weight and/or for an inadequate nutritional status during pregnancy, as following described. Thus, those women should be carefully screened and closely supervised by Health Professionals.

Women with multiple pregnancies are at high risk of delivering premature, with low body weight and with malformations newborns [58].

Pregnant adolescents should be carefully looked, since they are crossing a very demanding period of their own growth and development associated with increased energy needs for the growth and development of the fetus [59]. Adolescence is a period of life that diet is likely to be inadequate for energy intake and for some micronutrients, such as calcium, iron, zinc, riboflavin, folic acid and vitamins A, D and B-6. Therefore, it is recommended for pregnant adolescents to strive for weight gains toward the upper end of the ranges for women with similar weights for height [16].

Pregnant women who restrict or prohibit certain dietary practices or the consumption of important sources of energy and nutrients, as avoidance, for example of all animal foods (proteins) or milk (calcium, vitamin D) are at high risk of inadequate nutrient intakes. In these cases based on a poor diet quality and if a better food selection is not possible, selective supplementation is recommended by the IM [16].

Although there are no specific recommendations for micronutrients in athletes, female athletes practicing aesthetic sports, long-duration sports (marathons) and weight-categories sports (judo, canoeing) should take additional care towards their increased energy and nutritional needs in relation to pre-pregnancy and to their pairs (i.e. nonathlete women). These sports' athletes frequently present a reduced body weight that often leads to an inadequate energy intake, which can compromise them in achieving adequate energy levels for physiological functions, daily activities and physical activities [15]. The reason for this assumption lies in the fact that, in short term, energy availability is needed to improve athlete health and prevent injury. Sustained low energy availability may predispose these athletes to health hazards, such as irregular menstruation, infertility and osteoporosis $[15,60]$. Energy availability is defined as the amount of energy intake minus exercise energy expenditure normalized to fat-free mass $[60,61]$. Low energy availability is defined as energy availability below $45 \mathrm{kcal} / \mathrm{kg}$ fat-free mass/ day [62]. A threshold below $30 \mathrm{kcal} / \mathrm{kg}$ fat-free mass/day is associated with amenorrhea and is considered as the lowest energy threshold of energy availability for women $[15,61]$. In addition, the consumption of so called energydrinks is not recommended, because they normally present high amounts of caffeine [17].

The subcommittee of the IM recommends the application of a food frequency or a diet history questionnaire to assess more efficiently and practically the risk of dietary inadequacy in a pregnant woman [16]. According to the mentioned subcommittee, special groups of pregnant women 
such as those who do not usually practice a healthy diet and those who are in high-risk categories (pregnant women carrying more than one fetus, high cigarette smokers women, heavy alcohol consumers and drug abusers) should daily take a multivitamin-mineral preparation containing several nutrients mainly by the second trimester as follow: iron $=30$ $\mathrm{mg} /$ day, vitamin $\mathrm{B}-6=2 \mathrm{mg} /$ day, $\mathrm{zinc}=15 \mathrm{mg} /$ day, folate $=300 \mu \mathrm{g} / \mathrm{day}$, copper $=2 \mathrm{mg} /$ day, vitamin $\mathrm{C}=50 \mathrm{mg} /$ day, calcium $=250 \mathrm{mg} /$ day and vitamin $\mathrm{D}=5 \mu \mathrm{g} /$ day.

This subcommittee highlights that to improve absorption of these minerals and vitamins, this supplement should be taken between meals or at bedtime [16].

\section{The Newborn Nutrition}

Future mothers should be aware of their slightly higher energy and nutrients requirements during lactation [63].

In this article, it is supported the prevalence of breastfeeding, since it provides several benefits for the newborn. It should be observed that in pre-pregnancy and during pregnancy, not only women, but both future parents should be informed about the several advantages of breast feeding for both mother and infant [64]. The World Health Organization recommends breast milk as the ideal source of energy and nutrients for the infant growth up to the first 6 months [65]. That is why breastfeeding might be strongly supported as the ideal form of infant feeding, which should be promoted because of its multiple benefits for child health, and only when breast milk is not available, infant formula shall be introduced [17].

There are a number of benefits of the human milk, as follows: it is the only food that provides all the nutrients baby needs to be healthy and to develop a strong immune system (antibodies, immune factors, enzymes, and white blood cells); it protects the baby against a wide variety of diseases and infections that infant formula cannot offer. This type of feeding significantly decreases the chances of ear infections, vomiting, diarrhea, pneumonia, urinary tract infections, or spinal meningitis. Infants under 1-year old, who are breastfed exclusively for at least four months, are less likely to show lower respiratory tract infection, croup, bronchiolitis, or pneumonia, than formula-fed babies. Besides, human milk has prebiotic substances that encourage growth of healthy bacteria in the intestinal tract. So, breastfed babies generally present lower risk of milk allergy, atopic dermatitis (eczema) and wheezing if they were exclusively breastfed for at least 4 months [66]. After all, it is understood that a reduction in morbidity associated with breastfeeding is of great public health concern [67]. Therefore, the World Health Organization recommends the breast milk as the ideal source of energy and nutrients for the infant growth up to the first 6 months [65]. That is why breastfeeding might be strongly supported as the ideal form of infant feeding, which should be promoted, because of the multiple benefits for child health, and only when breast milk is not available, infant formula shall be introduced [17].

There are a number of benefits of the human milk, as it is the only food that provides all the nutrients baby needs to be healthy and to develop a strong immune system (antibodies, immune factors, enzymes, and white blood cells); it protects the baby diseases and infections that infant formula cannot offer. This type of feeding significantly decreases the chances of hospitalization. Besides, human milk has prebiotic substances that encourage the growth of healthy bacteria in the intestinal tract [66].

For those who by any reason are not able to be breastfeed, infant formula is the solution for infants less than 12 months of age. By definition, infant formula is a food that simulates human milk or is suitable as a complete or partial substitute for human milk. According to the Food Advisory Committee/Food and Drug Administration 1980 Infant Formula Act and 1986 amendments and the Food and Agriculture Organization/World Health Organization Codex Alimentarius [68, 69], it serves as the sole or the major source of nutrition during infancy, because of its simulation of human milk, or its suitability, as a complete or partial substitute for human milk. However, it is a product created by the food market based on cows' milk or other animals or a mixture of ingredients that has been proven to be suitable for infant feeding and meet the nutritional needs to promote growth and a regular development of the infants.

Nevertheless, the nutritional safety and adequacy of every infant formula must be scientifically demonstrated to support growth and development of infants. But since it is a created product, it cannot offer any error in the production; however, data from premarket clinical studies can be difficult to interpret or infants studied may not be sufficiently similar to infants for whom a new formula is intended to [65]. On the other hand, it is necessary to assume that breastfeeding for the first time may be not easy for some women. So, that is why mothers should have to learn how to do it and overcome the difficult considered natural for this moment, mainly for the first time. Thus, confidence and support to continue to breastfeed are essential [65].

In a recent study conducted among 51 in-depth interviews, the role of well-prepared health care providers and their family members (husband, grandparents) was the key to support mothers overcome any barrier and successfully breastfeed. Otherwise, the shift to infant formula may easily occur [70]. In another recent study it was highlighted the importance of not only family, but also friends on the breastfeeding intention. This study included 4690 woman in which it was found that breastfeeding preference occurred mostly when baby's fathers preferred exclusively breastfeeding. Authors highly recommend that family members along with pregnant mothers should be counseled on the benefits of breastfeeding and the risks of formula feeding [71].

As mentioned above, infant formula is to be used only when necessary, since some of the risks of artificial feeding exist, as the World Health Organization lists [69]. This process is not sterile and may be contaminated; may lack access to safe water to prepare and wash the bottles; may lack knowledge on proper use; people may over or under dilute the formula; the formula do not contain protective properties, such as antibodies found in breast milk; the poor sanitation also increases risk of contamination during preparation; and the supplies are often not sustainable, among others [64].

Other implications must be considered when bottlefeeding regardless the type of milk offered. For example, 
infants fed from the breast can control better milk intake, because they are the one deciding when to start and when to stop sucking, and the quality/flavor of milk delivered along the breast feeding is different along the feeding (watery in the beginning and fatter in the end), permitting the baby to control better their intake when they feel satiate [72]. Whereas bottle-feeding may not be able to self-regulate the milk intake, and babies are always encouraged to drink until the milk is finished. That is why the authors highly associate this fact to satiety control and obesity. Formula feeding stimulates a higher postnatal growth velocity, whereas breast-feeding promotes slower growth and a reduced likelihood of overweight and obesity, because of the unique composition, metabolic and physiological responses to human milk [73].

A small advantageous effect of breastfeeding on neurological status seems to be found, since breast milk presents longer-chain polyunsaturated fatty acids (mainly omega-3), which formula does not; this is fundamental for postnatal neurological development [74, 75]. However, a supplementation of omega-3 to mothers who breastfeed or to the infant formula itself remains unresolved [76].

After all these facts, we believe that breastfeeding is the best nutrition for infants, whereas infant formula may be of great utility when the first is not available for any reason. It should be also emphasized the body contact established between the mother and the infant during the act of breast feeding; thus, promotes positive feelings between the mother and the infant, such as affection, a skin-to-skin contact between the mother and the infant, love and security.

\section{CONCLUSION}

The consumption of whole food like whole grains, fruit, vegetables, low-fat dairy and lean meats can be preventive for an appropriate maternal weight and infant weight, and consequently, for a successful partum and postpartum. There still is no effective supplementation to prevent adverse perinatal consequences when in the presence of an inadequate nutritional maternal intake and in a short or a long-term. Supplements should only be used when there is a deficiency. However, special groups of pregnant women who do not usually practice a healthy diet, those who are in high-risk categories (pregnant women carrying more than one fetus, women who are high cigarette smokers, heavy alcohol consumers and drug abusers) and pregnant athletes should daily take a multivitamin-mineral preparation containing several nutrients beginning in the second trimester. An active and responsible lifestyle, including a healthy diet and an appropriate body weight are mandatory for each pregnant woman and it should be encouraged by Health and Physical Exercise Professionals, so they are likely to have beneficial outcomes on maternal and fetal outcomes. Although infant formula is the solution for infant who are less than 12 months of age and are not able to be breastfeed, breast milk is a unique source of energy and nutrients.

\section{CONFLICT OF INTEREST}

The authors confirm that this article content has no conflict of interest.

\section{ACKNOWLEDGEMENTS}

Both authors were responsible for the conception, design and writing the manuscript, therefore both authors approved the final version of the manuscript.

\section{REFERENCES}

[1] Grieger JA, Clifton VL. A Review of the Impact of Dietary Intakes in Human Pregnancy on Infant Birthweight. Nutrients 2014; 29; 7(1): 153-78.

[2] Tompkins WT, Wiehl DG. Nutritional deficiencies as a casual factor in toxemia and premature labor. Am J Obstet Gynecol 1951; 62: 898-919.

[3] Venkatachalam, P.S. Maternal nutritional status and its effect on the newborn. Bull World Health Organ 1962; 26: 193-201.

[4] Dodd JM, Grivell RM, Nguyen AM, et al. Maternal and perinatal health outcomes by body mass index category. Aust N Z J Obstet Gynaecol 2011; 51: 136-40.

[5] Guelinckx I, Devlieger R, Beckers K, et al. Maternal obesity: Pregnancy complications, gestational weight gain and nutrition. Obes Rev 2008; 9: 140-50.

[6] Kaiser LL, Allen L. Position of the American Dietetic Association: Nutrition and lifestyle for a healthy pregnancy outcome. J Am Diet Assoc 2002; 102: 1479-90.

[7] Blumfield ML, Hure AJ, Macdonald-Wicks L, et al. A systematic review and meta-analysis of micronutrient intakes during pregnancy in developed countries. Nutr Rev 2013; 71: 118-32.

[8] Perng W, Stuart J, Rifas-Shiman SL, et al. Preterm birth and longterm maternal cardiovascular health. Ann Epidemiol 2015; 25(1) 40-5

[9] Gillman MW, Rifas-Shiman SL, Kleinman K, et al. Developmental origins of childhood overweight: Potential public health impact Obesity (Silver Spring) 2008; 16: 1651-6.

[10] Callaway LK, Prins JB, Chang AM, et al. The prevalence and impact of overweight and obesity in an australian obstetric population. Med J Aust 2006; 184: 56-9.

[11] Ehrenberg HM, Mercer BM, Catalano PM. The influence of obesity and diabetes on the prevalence of macrosomia. Am J Obstet Gynecol 2004; 191: 964-8.

[12] Guelinckx I, Devlieger R, Beckers K, et al. Maternal obesity: Pregnancy complications, gestational weight gain and nutrition. Obes Rev 2008; 9: 140-50.

[13] Bosaeus M, Hussain A, Karlsson T, et al. A randomized longitudinal dietary intervention study during pregnancy: effects on fish intake, phospholipids, and body composition. Nutr J 2015; 2: 14(1): 1.

[14] Insel P, Turner RE, Ross D. Nutrition. 3th edition. Sudbury, USA: Jones and Bartlett Publishers. 2007.

[15] Silva M-R G, Paiva T. Low energy availability and low body fat of female gymnasts before an international competition, Eur J Sport Sci 2014; 16: 1-9.

[16] Institute of Medicine and National Research Council of the National Academies. Weight Gain during Pregnancy: Reexamining the Guidelines. Washington, DC, USA: Institute of Medicine and National Research Council of the National Academies. 2009.

[17] Koletzko B, Bauer CP, Bung P, et al. German national consensus recommendations on nutrition and lifestyle in pregnancy by the 'Healthy Start - Young Family Network'. Ann Nutr Metab 2013; 63(4): 311-22.

[18] Athukorala C, Rumbold AR, Willson KJ, et al. The risk of adverse pregnancy outcomes in women who are overweight or obese. BMC Pregnancy Childbirth 2010; 10: 56.

[19] Wallace JM, Horgan GW, Bhattacharya S. Placental weight and efficiency in relation to maternal body mass index and the risk of pregnancy complications in women delivering singleton babies. Placenta 2012; 33: 611-8.

[20] Huang L, Liu J, Feng L, et al. Maternal prepregnancy obesity is associated with higher risk of placental pathological lesions. Placenta 2014, 35: 563-9.

[21] Correia-Branco A, Keating E, Martel F. Maternal undernutrition and fetal developmental programming of obesity: The glucocorticoid connection. Reprod Sci 2015; 22(2): 138-45.

[22] Hochberg Z, Feil R, Constancia M, et al. Child health, developmental plasticity, and epigenetic programming. Endocr Rev 2011; 32: 159-224. 
[23] Rizzo GS, Sen S. Maternal obesity and immune dysregulation in mother and infant: A review of the evidence. Paediatr Respir Rev 2014; 22: S1526-0542(14)00114-6.

[24] Sen S, Iyer C, Klebenov D, et al. Obesity impairs cell-mediated immunity during the second trimester of pregnancy. Am. J. Obstet. Gynecol 2013; 208: e131-e138.

[25] Alanis MC, Steadman EM, Manevich Y, et al. Maternal obesity and placental oxidative stress in the first trimester. Obes Weight Loss Ther 2012; 2: 143.

[26] Schmatz M, Madan J, Marino T, et al. Maternal obesity: The interplay between inflammation, mother and fetus. J. Perinatol 2010; 30: 441-6.

[27] Food and Nutrition Board/Institute of Medicine. Dietary reference intakes for energy, carbohydrate, fiber, fat, fatty acids, cholesterol, protein and amino acids. Washington, DC: National Academies Press. 2005. Available from http://www.nap.edu/catalog.php? record_id $=10490$

[28] Food and Nutrition Board/Institute of Medicine. Dietary reference intakes for vitamin $\mathrm{A}$, vitamin $\mathrm{K}$, arsenic, boron, chromium, copper, iodine, iron, manganese, molybdenum, nickel, silicon, vanadium, and zinc. Washington, DC: National Academies Press. 2001. Available from http://www.nap.edu/catalog/10026.html

[29] Food and Nutrition Board/Institute of Medicine. Dietary reference intakes for thiamin, riboflavin, niacin, vitamin B6, folate, vitamin B12, pantothenic acid, biotin, and choline. Washington, DC: National Academies Press. 1999. Available from http://www.nap. edu/catalog.php?record id $=6015$

[30] Food and Nutrition Board/Institute of Medicine. Dietary reference intakes for vitamin $\mathrm{C}$, vitamin $\mathrm{E}$, selenium, and carotenoids. Washington, DC: National Academies Press. 2000. Available from http://www.nap.edu/catalog.php?record_id=9810

[31] Food and Nutrition Board/Institute of Medicine. Dietary reference intakes for calcium and vitamin D. Washington, DC: National Academies Press. 2011. Available from http://www.nap.edu/ catalog.php?record_id $=13050$.

[32] Food and Nutrition Board/Institute of Medicine. Dietary reference intakes for water, potassium, sodium, chloride, and sulfate. Washington, DC: National Academies Press. 2005. Available from http://www.nap.edu/catalog/10925.html

[33] Stephens TV, Payne M, Ball RO, et al. Protein Requirements of Healthy Pregnant Women during Early and Late Gestation Are Higher than Current Recommendations. J Nutr 2015; 145(1): 73-8.

[34] Breton C. The hypothalamus-adipose axis is a key target of developmental programming by maternal nutritional manipulation. J. Endocrinol 2013; 216: R19-R31.

[35] Christian P. Impact of the economic crisis and increase in food prices on child mortality: exploring nutritional pathways. J Nutr 2010; 140(1): 177S-81S.

[36] Yu X, Shan Z, Li C, et al. Iron deficiency, an independent risk factor for isolated hypothyroxinemia in pregnant and non-pregnant women of childbearing age in China. J Clin Endocrinol Metab. 2015; 100(4): 1594-601.

[37] Scholl TO. Maternal iron status: Relation to fetal growth, length of gestation, and iron endowment of the neonate. Nutr Rev 2011; 69 S1: S23-S29.

[38] Shastri L, Mishra PE, Dwarkanath P, et al. Association of oral iron supplementation with birth outcomes in non-anaemic South Indian pregnant women. Eur J Clin Nutr 2015; 69(5): 609-13.

[39] Czeizel AE, Dudas I. Prevention of the first occurrence of neuraltube defects by periconceptional vitamin supplementation. N Engl J Med 1992; 327: 1832-5

[40] Fung EB, Ritchie LD, Woodhouse LR, et al. Zinc absorption in women during pregnancy and lactation: A longitudinal study. Am J Clin Nutr 1997; 66: 80-8

[41] Kovacs CS. Bone metabolism in the fetus and neonate. Pediatr Nephrol 2013; 29: 793-803.

[42] Javaid MK, Crozier SR, Harvey NC, et al. Maternal vitamin D status during pregnancy and childhood bone mass at age 9 years: A longitudinal study. Lancet 2006; 367: 36-43.

[43] Lawlor DA, Wills AK, Fraser A, et al. Association of maternal vitamin D status during pregnancy with bone-mineral content in offspring: a prospective cohort study. Lancet 2013; 22; 381(9884): 2176-83

[44] National Health and Medical Research Council. Nutrient Reference Values for Australia and New Zealand Including Recommended
Dietary Intakes. Canberra, Australia: National Health and Medical Research Council. 2005

[45] Fayyaz F, Wang F, Jacobs RL, et al. Folate, vitamin B12, and vitamin B6 status of a group of high socioeconomic status women in the Alberta Pregnancy Outcomes and Nutrition (APrON) cohort. Appl Physiol Nutr Metab 2014; 39(12): 1402-8.

[46] Chen LW, Lim AL, Colega M, et al. Maternal folate status, but not that of vitamins B-12 or B-6, is associated with gestational age and preterm birth risk in a multiethnic Asian population. J Nutr 2015; 145(1): 113-20.

[47] Darnton-Hill I. 2013. Nutrition counselling during pregnancy Biological, behavioural and contextual rationale. World Health Organization. Available from: http:/www.who.int/elena/titles/bbc/ nutrition counselling pregnancy/en/.

[48] Øverby NC, Hillesund ER, Sagedal LR, et al. The Fit for Delivery study: rationale for the recommendations and test-retest reliability of a dietary score measuring adherence to 10 specific recommendations for prevention of excessive weight gain during pregnancy. Matern Child Nutr 2015; 11(1): 20-32

[49] Grøholt E, Stigum H, Nordhagen R. Overweight and obesity among adolescents in Norway: cultural and socio-economic differences. J Public Health 2008; 30: 258-65.

[50] Croezen S, Visscher TL, Ter Bogt NC, et al. Skipping breakfast, alcohol consumption and physical inactivity as risk factors for overweight and obesity in adolescents: results of the E-MOVO project. Eur J Clin Nutr 2009; 63: 405-12.

[51] Delva J, Johnston LD, O'Malley PM. The epidemiology of overweight and related lifestyle behaviors: racial/ethnic and socioeconomic status differences among American youth. Am J of Prevent Med 2007; 33: S178-S86.

[52] Larson NI, Nelson MC, Neumark-Sztainer D, et al. Making time for meals: meal structure and associations with dietary intake in young adults. J Am Diet Assoc 2009; 109: 72-9.

[53] Malik VS, Schulze MB, Hu FB. Intake of sugarsweetened beverages and weight gain: a systematic review. Am J Clinic Nutr 2006; 84: 274-88.

[54] Kant AK, Graubard BI, Atchison EA. Intakes of plain water, moisture in foods and beverages, and total water in the adult US population - nutritional, meal pattern, and body weight correlates: National Health and Nutrition Examination Surveys 1999-2006. Am J Clinic Nutr 2009; 90: 655-63.

[55] Yang Z, Huffman SL. Review of fortified food and beverage products for pregnant and lactating women and their impact on nutritional status. Matern Child Nutr 2011; 7S3: 19-43.

[56] Dolan GP, Stone DH, Briggs AH. A systematic review of continuous performance task research in children prenatally exposed to alcohol. Alcohol 2010; 45(1): 30-8.

[57] Jahanfar S, Jaafar SH. Effects of restricted caffeine intake by mother on fetal, neonatal and pregnancy outcome. Cochrane Database Syst Rev 2013; 28; 2: CD006965.

[58] van Baaren GJ, Peelen MJ, Schuit E, et al. Preterm birth in singleton and multiple pregnancies: evaluation of costs and perinatal outcomes. Eur J Obstet Gynecol Reprod Biol 2015; 3: 34-41.

[59] Brahmbhatt $\mathrm{H}$, Kågesten A, Emerson M, et al. Prevalence and determinants of adolescent pregnancy in urban disadvantaged settings across five cities. J Adolesc Health 2014; 55: 6S48-57.

[60] Loucks AB, Kiens B, Wright HH. Energy availability in athletes. J Sport Sci 2011; 29: S7-15

[61] Rodriguez NR, DiMarco NM, Langley S, et al. Position of the American Dietetic Association, Dietitians of Canada and the American College of Sports Medicine: Nutrition and Athletic Performance. J Am Diet Assoc 2009; 109: 509-27.

[62] Hoch AZ, Pajewski NM, Moraski L, et al. Prevalence of the female athlete triad in high school athletes and sedentary students. Clin J Sport Med 2009; 19(5): 421-428.

[63] Institute of Medicine and National Research Council of the Nationa Academies. Nutrition during pregnancy and lactation: An Implementation Guide. Washington, DC, USA: Institute of Medicine and National Research Council of the National Academies. 1992

[64] Girard AW, Olude O. Nutrition education and counselling provided during pregnancy: effects on maternal, neonatal and child health outcomes. Paediatr Perinat Epidemiol 2012; 26S1: 191-204.

[65] World Health Organization. 10 facts on breastfeeding. Geneva, Switzerland: World Health Organization. 2014. Available from http://www.who.int/features/factfiles/breastfeeding/en/ 
[66] Meek JY, Yu W, American Academy of Pediatrics. New Mother's Guide to Breastfeeding. The American Academy of Pediatrics. USA. 2011.

[67] Dewey KG, Heinig MJ, Nommsen-Rivers LA. Differences in morbidity between breast-fed and formula-fed infants. J Pediatrics 1995;126,5:696-702.

[68] Food and Drug Administration. Food Advisory Committee Meeting on Infant Formula - 1980 Infant Formula Act and 1986 amendments. Available from: http://www.fda.gov/ohrms/dockets/ ac/02/briefing/3852b1_01.htm

[69] WHO/FAO. Codex Âlimentarius. International Food Standard. Formerly CAC/RS 72-1972. Adopted as a world-wide Standard 1981. Amended 1983, 1985, 1987. Revision 2007. Amended 2011.

[70] Braimoh J, Davies L. When 'breast' is no longer 'best': Post-partum constructions of infant-feeding in the hospital. Soc Sci Med 2014; 28,123C: 82-9.

[71] Mueffelmann RE, Racine EF, Warren-Findlow J, et al. Perceived Infant Feeding Preferences of Significant Family Members and
Mother's Intention to Exclusively Breastfeed. J Hum Lact 2014; 13: pii: 0890334414553941. [Epub ahead of print].

[72] Li R, Fein SB, Grummer-Strawn LM. Do Infants Fed From Bottles Lack Self-regulation of Milk Intake Compared With Directly Breastfed Infants? Pediatrics 2010; 125(6): e1386-93.

[73] Oddy WH, Mori TA, Huang RC, et al. Early infant feeding and adiposity risk: from infancy to adulthood. Ann Nutr Metab 2014; 64(3-4): 262-70.

[74] Anderson JW, Johnstone BM, Remley DT. Breast-feeding and cognitive development: a meta-analysis. Am J Clin Nutr 1999; (70)4: 525-35.

[75] Lanting CI, Fidler V, Huisman M, Touwen BC, Boersma ER Neurological differences between 9-year-old children fed breastmilk or formula-milk as babies. The Lancet 1994; (344)8933: 1319-22.

[76] Craig L Jensen CL, Maude M, Anderson RE, Heird W. Effect of docosahexaenoic acid supplementation of lactating women on the fatty acid composition of breast milk lipids and maternal and infant plasma phospholipids. Am J Clin Nutr, 2000; (71)1: 292s-9s. 